\title{
Spatial heterogeneity in mortality and its impact on the population dynamics of Eurasian woodcocks
}

Guillaume Péron ${ }^{(1,2)}$ *

Yves Ferrand $^{(3)}$

Rémi Choquet ${ }^{(1)}$

Roger Pradel ${ }^{(1)}$

François Gossmann ${ }^{(4)}$

Claudine Bastat ${ }^{(4)}$

Isabelle Bauthian ${ }^{(5)}$

Romain Julliard ${ }^{(5)}$

Olivier Gimenez ${ }^{(1)}$

${ }^{(1)}$ Centre d'Ecologie Evolutive et Fonctionnelle UMR 5175. CNRS, 1919 Route de Mende 34293 Montpellier Cedex 5, France

(2) Utah State University, Dept. of Wildland Resources, 5230 Old Main Hill, Logan, 84322 UT, USA

(3) Office National de la Chasse et de la Faune Sauvage, Direction des Etudes et de la Recherche, SaintBenoist, 78610 Auffargis, France

(4) Office National de la Chasse et de la Faune Sauvage, Direction des Etudes et de la Recherche, 39 boulevard Albert Einstein, CS 42355, 44323 Nantes Cedex 3, France

(5) UMR 7204 MNHN-CNRS-UPMC Conservation des espèces, restauration et suivi des populations. CP 51, 55 rue Buffon, 75005 Paris, France

*Corresponding author: e-mail: peron guillaume@yahoo.fr

Running title: Spatial heterogeneity and seasonal woodcock survival 


\section{Abstract}

2 Spatial heterogeneity, especially in mortality risk, is a major factor shaping population dynamics.

3 Here we study the impacts of spatial heterogeneity in hunting pressure on the demography of

4 Eurasian woodcock Scolopax rusticola, a relatively long-lived migratory gamebird. We develop

5 capture-recapture-recovery models in which both seasonality and spatial variation in hunting

6 pressure are accounted for, and fit them to individual-based data collected across the French

7 wintering range (> 44,000 banded individuals) as well as recoveries from spring stopovers and

8 breeding grounds in Europe. Our results quantify spatial variation in survival probability in the

9 wintering areas. They highlight the role of source-sink dynamics involving juvenile settlement

10 decisions, as well as the importance of mortality outside the winter quarters. We also discuss the

11 impact of spatial heterogeneity for demographic parameter estimation and data collection at the

12 range scale. 


\section{Introduction}

14 Spatial variation in environmental factors shapes population dynamics (Hanski 1991; Ozgul et al.

15 2009). However, most studies focus on variation in habitat features (e.g., Ozgul et al. 2006;

16 Mueller et al. 2009). Predation pressure is another factor expected to vary spatially, which is

17 known to shape space use by prey species at the landscape scale (Kauffman et al. 2007), but does

18 not compulsorily depend on habitat features especially on a broader scale. Predation pressure can

19 thereby, independently from other factors, determine habitat quality. This is particularly true of

20 "human predation" (hunting), which is more linked to road access than to other habitat features,

21 and against which avoidance behaviors (e.g., Salo et al. 2008) are less likely to be effective than

22 against natural predation.

23 Here we focus on how spatial variation in hunting pressure shapes local population

24 dynamics in Eurasian woodcocks Scolopax rusticola that winter in France. In this long-lived

25 species (known to exceed 20 year old in the wild) with relatively low offspring production

26 (Hoodless and Coulson 1998; Ferrand et al. 2008), and known to live at low densities (Duriez et

27 al. 2005b, c), the prediction is that hunting pressure, via its impact on local survival rates, should

28 shape population dynamics (Pfister 1998; Nilsen et al. 2009). However, the rates at which local

29 populations are able to compensate for hunting mortality (e.g., via density-dependent variation in

30 mortality rates from other sources: Burnham and Anderson 1984) can markedly modify the shape

31 of that relationship.

32 Capture-recovery data and statistical analyses (Williams et al. 2002) can be made

33 spatially-explicit to investigate these issues (Royle and Dubovski 2001; Péron et al. 2011).

34 Moreover, the benefits of making survival and recovery probability estimates spatially-explicit go 
35 beyond the biological implications, since in many cases aggregating heterogeneous data over

36 large spatial scales can produce biased estimates of the average value of the parameters at stake

37 (Bauthian 2005; Fletcher et al. 2011). Yet, spatially-explicit analyses are computer-intensive,

38 data-hungry, and require the use of elaborate techniques, which reduces their general

39 applicability. Here we use a more easy to implement approach, based on a proxy derived from the

40 capture-recovery data, with the caveat that we cannot get rid of sampling covariance between the

41 proxy and survival estimates. This proxy is used to investigate and discuss the role of spatial

42 variation in hunting pressure in woodcock demography, as well as issues associated with data

43 collection and parameter estimation.

\section{$44 \quad$ Material and methods}

45 Previous works about the French-wintering woodcock population have highlighted dramatically

46 low survival probability (Hémery et al. 1978; Gossmann et al. 1994; Tavecchia et al. 2002,

47 providing survival estimates up to 1998). These previous estimates are nevertheless incompatible

48 with the observed population trend (Ferrand et al. 2008): there has been no decrease from 1990

49 onwards and even a probable increase in recent years. We were therefore interested in updating

50 the survival estimates, in order to detect a potential increase in survival probability after 1990, as

51 well as to correct some potential flaws of the previous studies. Firstly, previous banding efforts

52 were mainly concentrated around well-known, high woodcock density areas where hunting

53 pressure could be considered higher than on average. The geographic area that was sampled for

54 this analysis was much more exhaustive than previously, and included both highly and lightly

55 hunted areas. Secondly, we refined the analysis by 1) using data from both fall/winter and

56 spring/summer to document seasonal variation more precisely, which is important given the

57 migratory nature of the population and that documented spatial variation occurs in fall/winter, 2) 
58 allowing age effects on summer survival probability, 3) using a measure of hunting pressure to

59 account for spatial variation and varying contributions of the different banding locations to the

60 dataset, and 4) relieving a constraint of linear temporal variation that was put on recovery

61 probability in previous modeling efforts.

62 Data collection

63 Detail on the field procedures can be found in Gossmann et al. (1994) and Ferrand et al. (2008).

64 Briefly, on the winter grounds most woodcocks commute between night-time feeding grounds

65 (mainly meadows) where banding occurs, and day-time roost sites in forests, where hunting

66 occurs (Duriez et al. 2005a, c). Woodcocks are marked with metal rings from October to

67 February. Age determination (adult or juvenile) is done using plumage features (Ferrand and

68 Gossmann 2009), but males and females are not distinguishable. Recovered rings are reported to

69 the woodcock network group at the Office National de la Chasse et de la Faune Sauvage

70 (ONCFS; French Hunting and Wildlife Service). These recoveries occur on the wintering grounds

71 in France, but also during migration and on the breeding grounds in Eastern Europe. Recaptures

72 of banded birds occur during the banding sessions in winter in France. Here we used data

73 collected between October 1989 and February 2009 (20 years). These data come from 44,902

74 different individuals, 12,078 of which were recovered in France and 737 recovered in Eastern

75 Europe, plus 2,873 different recapture events in France.

76 Seasonal CR models for the French-wintering Woodcock population

77 Based on the result that woodcocks are very faithful to their wintering location both within and

78 among years (Gossmann et al. 1994), we considered the banding location as representative of the

79 location where an individual would spend most of its winters. Our multistate CR models adopted 
80 the general structure described by Lebreton (2005) and Gauthier and Lebreton (2008). They were

81 parameterized using season-specific survival probabilities $s_{t}$ (the probability for a bird to survive

82 during time step $t$ to $t+1$ ), recovery probabilities $r_{t}$ (the probability for a bird dying to have died

83 from hunting and been reported as such to the ONCFS woodcock network), and recapture

84 probabilities $p_{\mathrm{t}}$ (the probability for a bird already wearing a band to be trapped again during the

85 winter banding sessions at time step $t$, given that it is alive).

Recoveries in winter occurred in France and in summer in Eastern Europe and an effect of

87 season on recovery probability was therefore included in all models. Following Tavecchia et al.

88 (2002), yearly winter recovery probability was also divided between direct (same winter as the

89 banding) and indirect (subsequent winters) recovery probabilities. This effect accounted for

90 various phenomena (Williams et al. 2002, pp. 393-399), including the fact that most woodcocks

91 were submitted to only a part of their first hunting season, and variation in hunters' reporting rate.

92 A further technical issue was raised by the fact that banding and hunting occur roughly at

93 the same time in winter. In this study, we accounted for that feature by computing monthly winter

94 survival probabilities (denoted $\tilde{s}_{t}$ ) and raising that probability to the adequate power. Thus,

95 individuals banded in, e.g., December had a first winter survival probability of $s_{t_{1}}=\tilde{s}_{t_{1}}^{3}$, instead

96 of $s_{t_{1}}=\tilde{s}_{t_{1}}^{5}$ if they had been banded in October. We used program E-SURGE (version 1.6.4;

97 Choquet et al. 2009; Appendix 1).

98 Variation in survival probability, model selection and inference

99 We considered the following potential factors of variation in survival: 
100 1) Season: 'Winter $t$ ' was the period from October of the year $t$ to February of the year $t+1$.

101 'Summer $t$ ' was the period from March to September of the year $t+1$.

102 2) Age: We separated first-year (juveniles) and adults. The age effect could impact both winter 103 and summer survival

104 3) Year: one estimate per year (full effect), or linear trend.

105 4) Location: To characterize on a fine scale the spatial variation in hunting pressure (which would 106 be closer to the actual situation than broader geographical classifications), we separated banding 107 locations into classes based on a hunting pressure index (HPI) built as follows. For each banding 108 locality, we computed the percentage over the 20 year study period of the banded birds that were 109 recovered (shot and reported as such) less than 10km from their banding place (as opposed to 110 those recovered further away). Localities were then categorized into two groups corresponding to 111 above-median (high) and below-median (low) percentage of birds recovered within 10km. We 112 restricted the dataset to the 714 localities where at least 20 birds have been banded over the study 113 period. We computed HPI for the whole period, i.e., we looked at a temporal average of local 114 hunting pressure. Both during seasonal migration and during periods of deepest snow cover, 115 woodcocks transit through large geographic areas. The HPI can thereby be interpreted as a 116 comparison between the local hunting pressure (within the $10 \mathrm{~km}$ radius) and the average hunting 117 pressure (as encountered when wandering). More detail on HPI and the limits and advantages of 118 that approach are presented in Appendix 2. In particular, since HPI was computed from the same 119 CR data as survival and recovery, it shared a sampling variance with these parameters, which 120 reduced the power of the tests for the effect of hunting pressure. 
We considered 21 different combinations of the above four factors in our set of candidate

122 models (Table 1). The model selection followed a step by step procedure, in which we first

123 selected the structure for encounter probabilities (recovery and recapture) and then selected the

124 structure for survival probabilities (Table 1). We relied on AIC (Akaike Information Criterion;

125 Burnham and Anderson 2002) to select the preferred model in the set of 21 models. We found

126 local minima in the deviance (combinations of parameters values for which the likelihood surface

127 reached a peak that was not the absolute maximum), which were handled by, for each model,

128 running the optimization procedure several times starting from different sets of initial values.

129 Growth rate computation

130 With an offspring production of 1.8 per female per year (Hoodless and Coulson 1998; Ferrand et 131 al. 2008), and using post-breeding, two age class matrix population models, we obtained an

132 estimate of population growth rate $\lambda$ based on the survival estimates of the preferred CMR model.

133 We computed the growth rate specific to each of the HPI classes, for each year. Confidence

134 intervals around $\lambda$ estimates were computed using a bootstrap procedure (Givens and Hoeting

135 2005), in which we sampled 1000 times within the approximate normal distributions of the logit-

136 transformed survival probabilities (as provided by E-SURGE), and obtained the empirical

137 distribution of $\lambda$. All estimates of temporal variance were corrected for sampling variance using 138 equation 4.2 p. 263 in Burnham et al. 1987, solved using MAPLE.

\section{Results}

140 Model selection

141 The model selection procedure (Table 1) favored models in which HPI affected both survival and recovery probabilities. Other retained structures were the effect of age on survival probabilities in 
143 winter and summer, as well as between-year variation in winter and summer survival, winter

144 recovery and winter recapture probabilities (model \#17 in Table 1). Including time-dependence in

145 summer survival and summer recovery probabilities only moderately improved the fit (models

$146 \# 17$ vs. 18 and \#5 vs. 1), probably because of the relatively sparse data from the summer period.

147 Parameter estimates: seasonality, time, hunting pressure, and age-effects

148 Parameter estimates indicated that the high HPI localities were characterized by low survival

149 (difference between high and low HPI on the logit-scale: -0.91 \pm SE 0.03) and high recovery

150 probabilities (difference between high and low HPI on the logit-scale: $0.54 \pm$ SE 0.17),

151 suggesting a spatial cross-correlation between survival and recovery probabilities from different

152 locations, mediated by HPI. This correlation was not found when tested using temporal instead of

153 spatial variation (a posteriori correlation between time-specific winter survival and winter

154 recovery probabilities: $\mathrm{r}^{2}=0.07$ ). If reporting rate (the rate at which shot birds with a ring are

155 reported) did not depend on hunting pressure, the difference in recovery probability between low

156 and high HPI areas suggests that two-fold variation in hunting pressure were commonplace

157 between different locations.

158 Survival probability varied between years in a manner that suggested an increase with

159 time (Table 2, Fig. 1), but the AIC for the model with a temporal trend suggested that significant

160 variation remained around that trend (model \#21 vs. 17 in Table 1). Summer monthly survival

161 was generally lower than low-HPI winter monthly survival (Fig. 1; average monthly adult

162 summer survival: 0.95; temporal SD corrected for sampling variance: 0.014; average monthly

163 adult winter survival in low HPI areas: $0.97 \pm 0.0049)$. This meant that summer mortality

164 represented more than two thirds of all adult deaths in birds wintering in low-HPI areas (about 
165 half in high HPI areas). Both the comparison of the fit of model \#17 vs. 20 and Fig. 1 indicated

166 the lack of correlation between winter survival and survival during the following summer.

167 Juveniles had lower survival rates than adults, during both the winter and the summer 168 periods (difference between juvenile and adult monthly survival on the logit-scale: $-0.83 \pm \mathrm{SE}$

1690.20 in winter, $-0.58 \pm$ SE 0.23 in summer). Average yearly survival rate of adults was 0.61

170 (temporal SD corrected for sampling variance: 0.070 ) in low HPI areas and $0.49 \pm 0.067$ in high

171 HPI areas. Average yearly survival rate of juveniles was $0.47 \pm 0.078$ in low HPI individuals and

$1720.33 \pm 0.065$ in high HPI individuals. If conducted without accounting for spatial heterogeneity

173 (i.e., discarding the HPI effect from the preferred model), the average yearly survival rate was

$1740.59 \pm 0.084$ for adults and $0.43 \pm 0.10$ for juveniles (average $\pm S E$ over time). The statistical bias

175 on average survival due to unaccounted for heterogeneity was therefore low in this analysis.

176 Population growth rate

177 Over the 20-year-long study period the average growth rate was 1.05 in high HPI areas (temporal

178 SD corrected for sampling variance: 0.13$)$, and 1.27 in low HPI areas $( \pm 0.13)$. The average

179 growth rate over areas was $1.16( \pm 0.13)$.

180 At the beginning of the study period (1990-1995), $\lambda$ estimates indicated that the

181 population was locally not self-sustainable $(\lambda<1$ in high HPI areas; Fig. 2$)$. However, the

182 average $\lambda$ across areas was 1.04 (temporal SD corrected for sampling variance: 0.12 ; Fig. 2), thus

183 compatible with the observed trend in population counts. After 1995, both parts of the population

184 showed growth rates above one in most years (Fig. 2), thus again compatible with the observed

185 increase in population counts. The difference in local growth rate between high and low HPI

186 areas was significant in most years (95\% confidence intervals in Fig. 2). 


\section{Discussion}

188 Spatial heterogeneity and population dynamics

189 The population growth rate estimates were on average 12\% higher in low than in high HPI areas.

190 During the earlier years of the study (pre-1990), when survival probabilities were lower, this

191 probable effect of hunting pressure meant that high HPI areas were sinks while low HPI areas

192 were sources. The occurrence of local over-harvesting is also in agreement with previous survival

193 estimates which were mostly based on data collected in highly-hunted areas (Hémery et al. 1978;

194 Gossmann et al. 1994; Tavecchia et al. 2002). Yet, no local extinction has ever been reported.

195 Therefore, although they were obtained without taking temporal variation in fecundity into

196 account, these results suggest an important role for a source-sink dynamic between places of low

197 and high hunting pressure (Pulliam 1988; Novaro et al. 2000). Given what is known of woodcock

198 behavior, it is unlikely that sinks were repopulated by direct movements from low- to high-HPI

199 areas during the winter. Instead, we suggest that juvenile birds, when they first arrive on the

200 wintering grounds, may distribute themselves more or less independently of hunting pressure, or

201 via density-dependent dispersal, may settle more often in depleted areas. The latter mechanism

202 was observed experimentally in Brittany where the removal of adult birds allowed juveniles to

203 occupy free forest sites (Fadat 1981). We thus believe that juveniles regularly replenish high HPI

204 areas. In agreement with this hypothesis and with Fadat (1981), we found that low HPI areas have

205 lower age ratios (number of juveniles per adult among recovered individuals) than high HPI areas

206 (unpublished result). 
208 Woodcocks have a slower life history than most gamebird species, especially those facing the 209 same hunting pressure. As such, woodcocks' population dynamics should be more sensitive than 210 other gamebirds' to changes in adult survival probability (Pfister 1998). Furthermore, woodcock 211 natural mortality rate (i.e., from causes other than hunting) should be more "canalised" (Stearns 212 and Kawecki 1994; Gaillard and Yoccoz 2003), conferring woodcock populations lower ability to 213 compensate for hunting mortality by changes in natural mortality. The latter prediction is 214 reinforced by the fact that woodcocks also live in a lower density than other gamebirds, and thus

215 density regulation is less likely to induce compensatory mortality (Williams et al. 2002). In agreement, our study showed a change in survival probability between locations with high and

217 low hunting pressures that was larger than observed in galliformes (Rolland et al. 2010; Besnard 218 et al. 2010; Sandercock et al. 2011, studying respectively Northern bobwhites, Pyrenean grey 219 partridges, and Willow ptarmigan). Although it is difficult to draw definitive conclusions from 220 four data points, we suggest nevertheless that woodcock survival shows a more direct response to 221 hunting pressure than galliformes, which a direct estimation of compensation rates could confirm.

222 Seasonality

223 For woodcocks that wintered in low-HPI areas, mortality on the spring staging and breeding 224 grounds ('summer') was clearly not negligible. The determinants of this relatively high mortality 225 outside of the wintering grounds remain unknown, and could include weather (cold springs, 226 droughts and fires in summer: Gossmann et al. 2011; Sepik et al. 1983), predation (on nesting 227 females as well as displaying males; Hoodless and Hirons 2007; Widén 1987) and spring hunting 228 (on displaying males; Blokhin et al. 2006). 
Winter and summer survival did not show any correlation over time, either positive or

230 negative. We did not find that summer survival was higher after a winter of high mortality, which

231 would have been predicted under the hypothesis of summer compensation for hunting mortality

232 (Boyce et al. 1999). Similarly, the absence of a positive relationship between winter and summer

233 survival contradicted the hypothesis of a carry-over effect (effect of winter harshness on survival

234 during the next breeding season). Eventually, since there was no synchrony between the

235 variation in winter and summer survival, the potential weather-related drivers of survival

236 probability in the different phases of the yearly cycle are likely local, i.e. not related to a global

237 scale climate variable.

238 Implications for parameter estimation and data collection

239 The existence of spatial variation in hunting pressure, which was mirrored in the survival rate,

240 raises two issues. 1) The spatial distribution of sampling effort (capture of un-banded woodcocks)

241 may not compulsorily match the spatial distribution of hunting pressure, especially at a large

242 (country) scale. Thereby, some part of the survival distribution may be over-represented in the

243 data, flawing the overall survival estimate if it is not made spatially explicit. In our case, we

244 suspect a bias towards highly-hunted areas, because these are also areas of high woodcock

245 density and because knowledge about woodcock presence in non-hunted locations may be

246 limited. 2) If not accounted for in the survival model, spatial variation in hunting pressure may

247 lead to a statistical bias, i.e., the inability of the model fitting method to retrieve the actual

248 average of survival probability within sampled individuals. Unpublished simulation-based

249 estimation of this bias suggests it can often be large (Bauthian 2005), though in our case we

250 estimated a small effect only. Both issues are related to the recurrent problem of individual 
251 heterogeneity in capture-recapture models (Carothers 1973; Nichols 1982; Royle 2008; Pradel 252 2009) and require further investigation.

253 In conclusion, by adding a spatial component to a seasonal CR model, we obtained

254 insights into the extent to which spatial heterogeneity in winter mortality patterns could

255 potentially shape population dynamics of a migratory species. The proportion of individuals that

256 winters in high HPI areas likely determines to a large extent the country-level woodcock

257 population growth rate. This suggests a way for managers to act upon that growth rate by

258 spatially regulating hunting access or intensity, where possible. Our results also highlight the

259 importance of fluxes of individuals into high-HPI areas (most probably juveniles). Lastly, they

260 illustrate that potential biases linked to data collection and model fitting can be avoided by

261 making survival estimates spatially explicit.

262 Acknowledgements. Nothing would have been possible without the important field work and

263 dynamism of the banders of the ONCFS/FNC/FDC Woodcock Network. This research was

264 supported in part by a Quinney post-doctoral fellowship at Utah State University to G.P and a

265 grant ANR-08-JCJC-0088-01 from Agence nationale de la Recherche to O.G. We are grateful for

266 the contribution of an anonymous reviewer, as well as to O. Duriez and D. Koons for

267 commenting on previous drafts.

\section{References}

269 Bauthian I (2005) Dynamiques spatiales des espèces d'intérêt cynégétique. L'apport des modèles 270 de dynamique de populations. PhD Thesis. Université Pierre et Marie Curie - Paris 6.

271 Besnard A, Novoa C, Gimenez O (2010) Hunting impact on the population dynamics of Pyrenean 272 grey partridge Perdix perdix hispaniensis. Wildlife Biology 16: 135-143 
273

274

275

276

277

278

279

280

281

282

283

284

285

286

287

288

289

290

291

292

293

294

295

Blokhin YY, Mezhnev AP, Fokin SY (2006) Woodcock hunting bag statistics in Russia since 1996. In Ferrand Y (ed) Sixth European Woodcock and Snipe Workshop - Proceedings of an International Symposium of the Wetlands International Woodcock and Snipe Specialist Group, 25-27 November 2003, Nantes, France. Wetlands International Global Series $\mathrm{N}^{\circ} 18$, International Wader Studies 13, Wageningen, The Netherlands. pp. 16-22.

Boyce MS, Sinclair ARE, White GC (1999) Seasonal compensation of predation and harvesting. Oikos 87: 419-426.

Burnham KP, Anderson DR (1984) Tests of compensatory versus additive mortality in Mallards. Ecology 65:105-112.

Burnham KP, Anderson DR, White, GC, Brownie C, Pollock, KP (1987) Design and analysis methods for fish survival experiments based on release-recapture. Bethesda, MD: American Fisheries Society Monograph 5.

Carother AD (1973) Effects of unequal catchability on Jolly-Seber estimates. Biometrics 29: 79100.

Choquet R, Rouan L, Pradel R (2009) Program E-SURGE: a software application for fitting Multievent models. Modeling Demographic Processes In Marked Populations (eds Thomson DL, Cooch EG, Conroy MJ), pp. 845-865. Springer, New York.

Duriez O, Eraud C, Barbraud C, Ferrand Y (2005a) Factors affecting population dynamics of Eurasian woodcocks wintering in France: assessing the efficiency of a hunting-free reserve. Biological Conservation 122: 89-97.

Duriez O, Ferrand Y, Binet F, Corda E, Gossmann F, Fritz H (2005b) Habitat selection of the Eurasian woodcock in winter in relation to earthworms availability. Biological Conservation 122: 479-490. 
296

297

298

299

300

301

302

303

304

305

306

307

308

309

310

311

312

313
Duriez O, Fritz H, Said S, Ferrand Y (2005c) Wintering behaviour and spatial ecology of Eurasian Woodcock Scolopax rusticola in western France. Ibis 147: 519-532.

Fadat C (1981) Age-ratio des tableaux de chasse de bécasses (Scolopax rusticola). Signification biologique et utilisation pour la bonne gestion des populations bécassières. Bulletin mensuel ONC, n Spécial Scientifique et Technique, novembre 1981: 141-172.

Ferrand Y, Gossmann F, Bastat C, Guénézan M (2008) Monitoring of the wintering and breeding Woodcock populations in France. Revista Catalana d'Ornitologia 24: 44-52.

Ferrand Y, Gossmann F (2009) Ageing and sexing series 5: Ageing and sexing the Eurasian Woodcock Scolopax rusticola. Wader Study Group Bull. 116: 75-79.

Fletcher D, Lebreton J-D, Marescot L, Schaub M, Gimenez O, Dawson S, Slooten E (2011) Bias in estimation of adult survival and asymptotic population growth rate caused by undetected capture heterogeneity. Methods in Ecology and Evolution. In press.

Gaillard JM, Yoccoz NG (2003) Temporal variation in survival of mammals: A case of environmental canalization? Ecology 84: 3294-3306.

Gauthier G, Lebreton JD (2008) Analysis of band-recovery data in a multistate capture-recapture framework. Canadian Journal of Statistics-Revue Canadienne De Statistique 36: 59-73.

Givens GH, Hoeting JA (2005) Computational Statistics. Wiley, New York.

Gossmann F, Ferrand Y, Bastat C (1994) Mortalité hivernale des bécasses des bois en France d'après les reprises de bagues. IWRB Publication 31: 8-14.

Gossmann F, Boidot JP, Bastat C, Ferrand Y (2011) Effects of summer 2010 drought in European Russia on the migrating and wintering Woodcock population in France. Comm. 7th Woodcock and Snipe Specialist Group Workshop. 16-18 May 2011. Saint Petersburg (Russia). 
319 Givens GH, Hoeting JA (2005) Computational Statistics. - Wiley Series in Probability and $320 \quad$ Statistics, Hoboken, New Jersey, USA. 418 pp.

321 Hanski I (1991) Metapopulations dynamics: empirical and theoretical investigations. Biol. J. 322 Linn. Soc. Academic Press, London.

323 Hémery G, Jarry G, Le Toquin A, Nicolau-Guillaumet P (1978) Etudes préliminaires des populations de Bécasses des bois migratrices et hivernantes en France. Bulletin mensuel de l'Office National de la Chasse, numéro spécial sciences et techniques 1978: 5-37.

Hoodless AN, Coulson JC (1998) Breeding biology of the woodcock Scolopax rusticola in Britain. Bird Study 45: 195-204.

Hoodless AN, Hirons GJM (2007) Habitat selection and foraging behaviour of breeding Eurasian Woodcock Scolopax rusticola: a comparison between contrasting landscapes. Ibis 149 (Suppl.2): 234-249.

Kauffman MJ, Varley N, Smith DW, Stahler DR, MacNulty DR, Boyce MS (2007) Landscape heterogeneity shapes predation in a newly restored predator-prey system. Ecology Letters New Zealand Journal of Statistics 47: 49-63. determines habitat suitability for a territorial generalist. Ecography 32: 345-353. 10: 690-700.

Lebreton JD (2005) Dynamical and statistical models for exploited populations. Australian and

Mueller T, Selva N, Pugacewicz E, Prins E (2009) Scale-sensitive landscape complementation

Nichols JD, Stokes SL, Hines JE, Conroy MJ (1982) Additional comments on the assumption of homogeneous survival rates in modern bird banding estimation models. Journal of Wildlife Management 46: 953-962. 
341

Nilsen EB, Gaillard JM, Andersen R, Odden J, Delorme D, van Laere G, Linnell JDC (2009) A slow life in hell or a fast life in heaven: demographic analyses of contrasting roe deer populations. Journal of Animal Ecology 78: 585-594.

Novaro AJ, Redford KH, Bodmer RE (2000) Effect of hunting in source-sink systems in the neotropics. Conservation Biology 14: 713-721.

Ozgul A, Armitage KB, Blumstein DT, Vanvuren DH, Oli MK (2006) Effects of patch quality and network structure on patch occupancy dynamics of a yellow-bellied marmot metapopulation. Journal of Animal Ecology 75: 191-202.

Ozgul A, Oli MK, Armitage KB, Blumstein DT, Van Vuren DH (2009) Influence of Local Demography on Asymptotic and Transient Dynamics of a Yellow-Bellied Marmot Metapopulation. American Naturalist 173: 517-530.

Péron G, Ferrand Y, Gossmann F, Bastat C, Guénézan M, Gimenez O (2011) Nonparametric spatial regression of survival probability: visualization of population sinks in Eurasian Woodcock. Ecology preprint: doi:10.1890/10-2224.1.

Pfister CA (1998) Patterns of variance in stage-structured populations: Evolutionary predictions and ecological implications. Proceedings Of The National Academy Of Sciences Of The United States Of America 95: 213-218.

Pradel R (2009) The stakes of capture-recapture models with state uncertainty. - In: Thomson, D. L. et al. (eds), Modeling demographic processes in marked populations. Springer, pp. $781-795$.

Pulliam HR (1988) Sources, sinks, and population regulation. American Naturalist 132: 652-661. Rolland V, Hostetler JA, Hines TC, Percival HF, Oli MK (2010) Impact of harvest on survival of a heavily hunted game bird population. Wildlife Research 37: 392-400. 
364 Royle JA, Dubovsky JA (2001) Modeling spatial variation in waterfowl band-recovery data. $365 \quad$ Journal of Wildlife Management 65: 726-737.

366 Royle JA (2008) Modeling individual effects in the Cormack-Jolly-Seber model: a state-space 367 formulation. Biometrics 64: 364-370.

368 Salo P, Nordstrom M, Thomson RL, Korpimaki E (2008) Risk induced by a native top predator 369 reduces alien mink movements. Journal of Animal Ecology 77: 1092-1098.

370 Sandercock BK, Nilsen EB, Broseth H, Pedersen HC (2011) Is hunting mortality additive or compensatory to natural mortality? Effects of experimental harvest on the survival and cause-specific mortality of willow ptarmigan. Journal of Animal Ecology 80: 244-258.

373 Sepik GF, Owen RB, Dwyer TJ (1983) The effect of drought on a local Woodcock population. 374 Trans. of the Northeast Section, The Wildlife Society, 40th Northeast Fish \& Wildlife 375 Conference, 15-18 May 1983, West Dover, Vermont, USA. 1-8

376 Stearns SC, Kawecki TJ (1994) Fitness sensitivity and the canalization of life-history traits. $377 \quad$ Evolution 48:1438-1450.

378 Tavecchia G, Pradel R, Gossmann F, Bastat C, Ferrand Y, Lebreton JD (2002) Temporal 379 variation in annual survival probability of the Eurasian woodcock Scolopax rusticola 380 wintering in France. Wildlife Biology 8: 21-30.

381 Widén P (1987) Goshawk predation during winter, spring and summer in a boreal forest area of 382 central Sweden. Holarctic Ecology 10:104-109.

383 Williams BK, Nichols JD, Conroy MJ (2002) Analysis and management of animal populations. 384 Academic Press, San Diego, California. 


\section{Tables}

Table 1. Step-by-step model selection for woodcock survival $\left(s_{a, s, t}\right)$, recapture $\left(p_{t}\right)$ and recovery $\left(r_{\mathrm{s}, t}\right)$ probabilities. In the description of the effects, $W$ and $S$ stand for winter and summer, $a$ stands for age (juveniles $v s$. adults), $t$ stands for complete year-effect (20 parameters), $T$ for linear year effect (2 parameters) and HPI stands for hunting pressure index (2 levels). A dot indicates a constant parameter. + and $*$ are the usual operators for additive and interacting effects. A semicolon separates models for winter and summer probabilities. For example ' $W(\mathrm{HPI}) ; S()+$.$a '$ indicates that the effect of $a$ is additive to the effect of season, that there is no year effect and that HPI affects the winter probability. Given are model numbers (\#), description of the effects on survival $\left(s_{a, s, t}\right)$, recapture $\left(p_{t}\right)$ and recovery $\left(r_{s, t}\right)$ probabilities, number of parameters $(\mathrm{np})$, Deviance, difference in Akaike Information Criterion to the preferred model ( $\triangle \mathrm{AIC})$ and a short description of the model biological meaning and difference from neighbouring models. For each step of the model selection, the preferred model is indicated in bold. $\triangle \mathrm{AIC}$ is computed globally, i.e., represents the distance to the overall preferred model.

\begin{tabular}{|c|c|c|c|c|c|c|c|}
\hline \# & $s_{a, s, t}$ & $p_{t}$ & $r_{\mathrm{s}, t}$ & $\# \mathrm{p}$ & Dev & $\Delta \mathrm{AIC}$ & Biological meaning \\
\hline \multicolumn{8}{|c|}{ Selection for the time-dependency of recovery and recapture probabilities } \\
\hline 1 & $W(a+\mathrm{HPI}) ; S(a)$ & $t$ & $\begin{array}{l}W(t+\mathrm{HPI}) \\
\quad S(t)\end{array}$ & 65 & 81373.2 & 103.2 & $\begin{array}{l}\text { year-effect on all observation } \\
\text { parameters }\end{array}$ \\
\hline 2 & $W(a+\mathrm{HPI}) ; S(a)$ & $t$ & $W(\mathrm{HPI}) ; S()$. & 29 & 82548.7 & 1206.7 & $\begin{array}{l}\text { year-effect on recapture } \\
\text { probabilities only }\end{array}$ \\
\hline 3 & $W(a+\mathrm{HPI}) ; S(a)$ & . & $\begin{array}{l}W(t+\mathrm{HPI}) \\
\quad S(t)\end{array}$ & 47 & 81453.3 & 147.3 & $\begin{array}{l}\text { year-effect on winter and } \\
\text { summer recovery probabilities }\end{array}$ \\
\hline 4 & $W(a+\mathrm{HPI}) ; S(a)$ & . & $\begin{array}{l}W(t+\mathrm{HPI}) \\
\quad S(.)\end{array}$ & 28 & 81468.0 & 124.0 & $\begin{array}{l}\text { year-effect on winter recovery } \\
\text { probabilities only }\end{array}$ \\
\hline 5 & $W(a+H P I) ; S(a)$ & $t$ & $W(t+\mathbf{H P I})$ & 47 & 81406.7 & 100.7 & year-effect on winter recovery \\
\hline
\end{tabular}


$S($.

$6 \quad W(a+\mathrm{HPI}) ; S(a) \quad . \quad W(\mathrm{HPI}) ; S() \quad 11 \quad 81701.2 \quad$.

$7 \quad W(a+\mathrm{HPI}) ; S(a) \quad t \quad W(T+\mathrm{HPI})$;

$S($.

$8 \quad W(a+\mathrm{HPI}) ; S(a) \quad T \quad W(t+\mathrm{HPI})$

$S($. and recapture probabilities

No year-effect on observation

parameters

Best model above with linear

$\begin{array}{llll}30 & 81474.8 & 134.8 & \text { temporal trend on recovery }\end{array}$

probabilities

Best model above with linear

$\begin{array}{llll}29 & 81471.9 & 129.9 & \text { temporal trend on recapture }\end{array}$ probabilities

Selection for the presence of HPI effect on survival and recovery parameters

\begin{tabular}{|c|c|c|c|c|c|c|c|}
\hline 5 & $W(a+H P I) ; S(a)$ & $t$ & $\begin{array}{c}W(t+\mathrm{HPI}) \\
S(.)\end{array}$ & 47 & 81406.7 & 100.7 & $\begin{array}{l}\text { HPI-effect on both survival and } \\
\text { recovery probabilities }\end{array}$ \\
\hline 9 & $W(a+\mathrm{HPI}) ; S(a)$ & $t$ & $W(t) ; S()$. & 45 & 82023.2 & 713.2 & $\begin{array}{l}\text { HPI-effect on survival } \\
\text { probabilities only }\end{array}$ \\
\hline 10 & $W(a) ; S(a)$ & $t$ & $\begin{array}{l}W(t+\mathrm{HPI}) \\
\quad S(.)\end{array}$ & 45 & 82243.9 & 933.9 & $\begin{array}{l}\text { HPI-effect on recovery } \\
\text { probabilities only }\end{array}$ \\
\hline 11 & $W(a) ; S(a)$ & $t$ & $W(t) ; S()$. & 44 & 82696.4 & 1384.4 & no HPI effect \\
\hline
\end{tabular}

Selection for the effect of age on survival parameters

\begin{tabular}{|c|c|c|c|c|c|c|c|}
\hline 5 & $W(a+\mathbf{H P I}) ; S(a)$ & $t$ & $\begin{array}{c}W(t+H P I) \\
S(.)\end{array}$ & 47 & 81406.7 & 100.7 & $\begin{array}{l}\text { Age-effect on both winter and } \\
\text { summer survival probabilities }\end{array}$ \\
\hline 12 & $W(a+\mathrm{HPI}) ; S()$. & $t$ & $\begin{array}{c}W(t+\mathrm{HPI}) \\
S(.)\end{array}$ & 45 & 81499.4 & 189.4 & $\begin{array}{l}\text { Age-effect on winter survival } \\
\text { probabilities only }\end{array}$ \\
\hline 13 & $W(\mathrm{HPI}) ; S(a)$ & $t$ & $\begin{array}{l}W(t+\mathrm{HPI}) \\
\quad S(.)\end{array}$ & 45 & 81660.0 & 350.0 & $\begin{array}{l}\text { Age-effect on summer survival } \\
\text { probabilities only }\end{array}$ \\
\hline 14 & $W(\mathrm{HPI}) ; S()+a$. & $t$ & $\begin{array}{l}W(t+\mathrm{HPI}) \\
\quad S(.)\end{array}$ & 45 & 81430.5 & 120.5 & $\begin{array}{l}\text { Same age-effect on winter and } \\
\text { summer survival probabilities }\end{array}$ \\
\hline 15 & $W(\mathrm{HPI}) ; S()$. & $t$ & $\begin{array}{c}W(t+\mathrm{HPI}) \\
S(.)\end{array}$ & 44 & 81749.7 & 437.7 & No age-effect \\
\hline
\end{tabular}

Selection for the time-dependency of survival parameters

$5 \quad W(a+\mathrm{HPI}) ; S(a) \quad t \quad W(t+\mathrm{HPI})$

$\begin{array}{lll}47 & 81406.7 & 100.7\end{array}$

No year-effect on survival

probabilities 


\begin{tabular}{|c|c|c|c|c|c|c|c|}
\hline 16 & $\begin{array}{c}W\left(a^{*} t+\mathrm{HPI}\right) \\
S\left(a^{*} t\right)\end{array}$ & $t$ & $\begin{array}{l}W(t+\mathrm{HPI}) \\
S(.)\end{array}$ & 120 & 81177.3 & 17.3 & $\begin{array}{l}\text { Year-effect on winter and } \\
\text { summer survival probabilities, } \\
\text { acting differently among age- } \\
\text { classes }\end{array}$ \\
\hline 17 & $\begin{array}{c}W(a+t+\mathrm{HPI}) \\
S(a+t)\end{array}$ & $t$ & $\begin{array}{c}W(t+\mathbf{H P I}) ; \\
S(.)\end{array}$ & 83 & 81234.0 & $\mathbf{0}$ & $\begin{array}{l}\text { Year-effect on winter and } \\
\text { summer survival probabilities, } \\
\text { additive to age-effect }\end{array}$ \\
\hline 18 & $W(a+t+\mathrm{HPI}) ; S(a)$ & $t$ & $\begin{array}{l}W(t+\mathrm{HPI}) \\
S(.)\end{array}$ & 65 & 81276.9 & 6.9 & $\begin{array}{l}\text { Year-effect on winter survival } \\
\text { probabilities only }\end{array}$ \\
\hline 19 & $W(a+\mathrm{HPI}) ; S(a+t)$ & $t$ & $\begin{array}{l}W(t+\mathrm{HPI}) \\
\quad S(.)\end{array}$ & 64 & 81358.9 & 86.9 & $\begin{array}{l}\text { Year-effect on summer survival } \\
\text { probabilities only }\end{array}$ \\
\hline 20 & $\begin{array}{c}W(a+\mathrm{HPI}) ; S(a) \\
+t\end{array}$ & $t$ & $\begin{array}{l}W(t+\mathrm{HPI}) \\
S(.)\end{array}$ & 65 & 81288.5 & 18.5 & $\begin{array}{l}\text { Same year-effect on winter and } \\
\text { summer survival probabilities }\end{array}$ \\
\hline 21 & $\begin{array}{c}W(a+T+\mathrm{HPI}) \\
S(a+T)\end{array}$ & $t$ & $\begin{array}{l}W(t+\mathrm{HPI}) \\
S(.)\end{array}$ & 48 & 81331.5 & 27.5 & $\begin{array}{l}\text { Best model above with linear } \\
\text { temporal trend on winter and } \\
\text { summer survival probabilities }\end{array}$ \\
\hline
\end{tabular}


Table 2: Annual survival probability and winter recovery probability of adult woodcock wintering in low HPI areas, with standard deviation (SE). Age effect (adult/juvenile) and hunting pressure effect (low/high HPI) were additive to that temporal variation and are presented in the main text. 'Year' start in October, e.g. 1989 stands for winter 1989-1990 and summer 1990. All estimates are from the preferred model 17 in Table 1.

\begin{tabular}{|c|c|c|c|c|}
\hline Year & Survival & SE & Recovery & SE \\
\hline 1990 & 0.426 & 0.039 & 0.107 & 0.024 \\
\hline 1991 & 0.619 & 0.027 & 0.275 & 0.082 \\
\hline 1992 & 0.606 & 0.030 & 0.151 & 0.041 \\
\hline 1993 & 0.626 & 0.035 & 0.177 & 0.059 \\
\hline 1994 & 0.505 & 0.025 & 0.090 & 0.016 \\
\hline 1995 & 0.640 & 0.018 & 0.224 & 0.044 \\
\hline 1996 & 0.723 & 0.016 & 0.392 & 0.113 \\
\hline 1997 & 0.493 & 0.020 & 0.090 & 0.012 \\
\hline 1998 & 0.629 & 0.021 & 0.167 & 0.032 \\
\hline 1999 & 0.623 & 0.019 & 0.112 & 0.019 \\
\hline 2000 & 0.666 & 0.018 & 0.137 & 0.025 \\
\hline 2001 & 0.605 & 0.017 & 0.171 & 0.024 \\
\hline 2002 & 0.543 & 0.018 & 0.090 & 0.011 \\
\hline 2003 & 0.699 & 0.019 & 0.190 & 0.043 \\
\hline 2004 & 0.617 & 0.017 & 0.141 & 0.021 \\
\hline 2005 & 0.585 & 0.018 & 0.122 & 0.016 \\
\hline 2006 & 0.678 & 0.019 & 0.146 & 0.028 \\
\hline
\end{tabular}


$\begin{array}{lllll}2007 & 0.604 & 0.025 & 0.138 & 0.025\end{array}$

$\begin{array}{lllll}2008 & 0.753 & 0.015 & 0.245 & 0.056\end{array}$ 


\section{Figures legends}

Figure 1. Monthly survival probabilities of adult woodcocks in summer (grey lines) and winter (black lines; lower line for high HPI and higher line for low HPI areas). Dotted lines: 95\% confidence intervals. All estimates are from the preferred model 17 in Table 1.

Figure 2. Annual population growth rate in low HPI (black lines) and high HPI (grey lines) areas. Dotted lines: $95 \%$ confidence intervals.

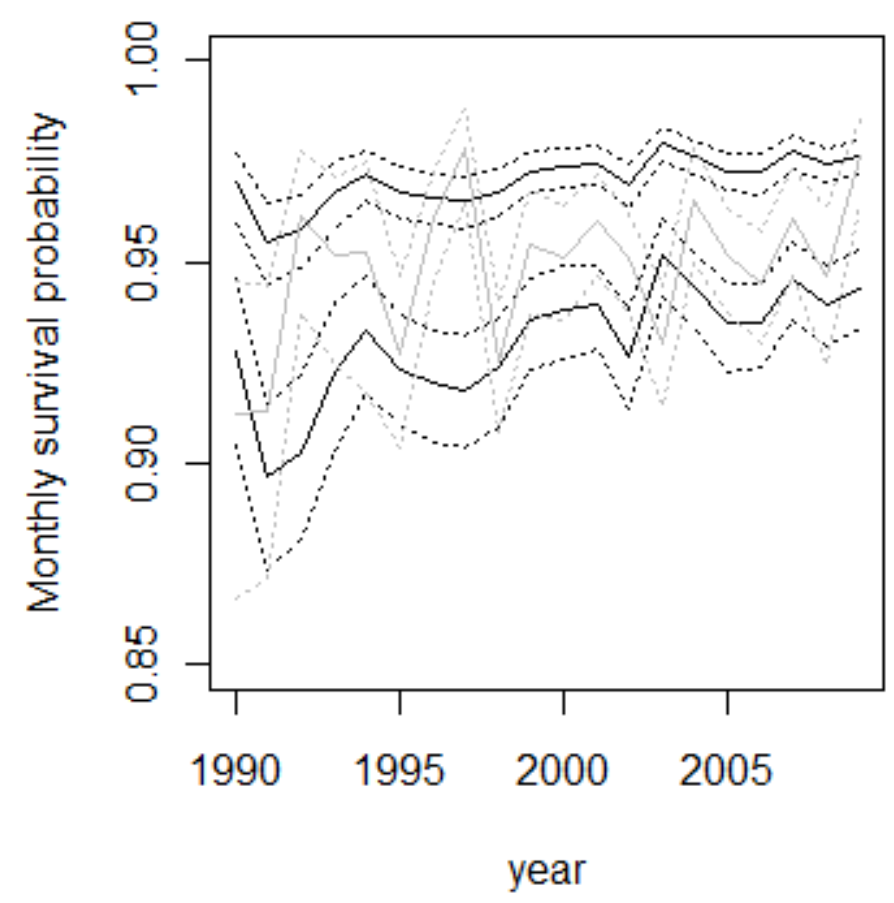




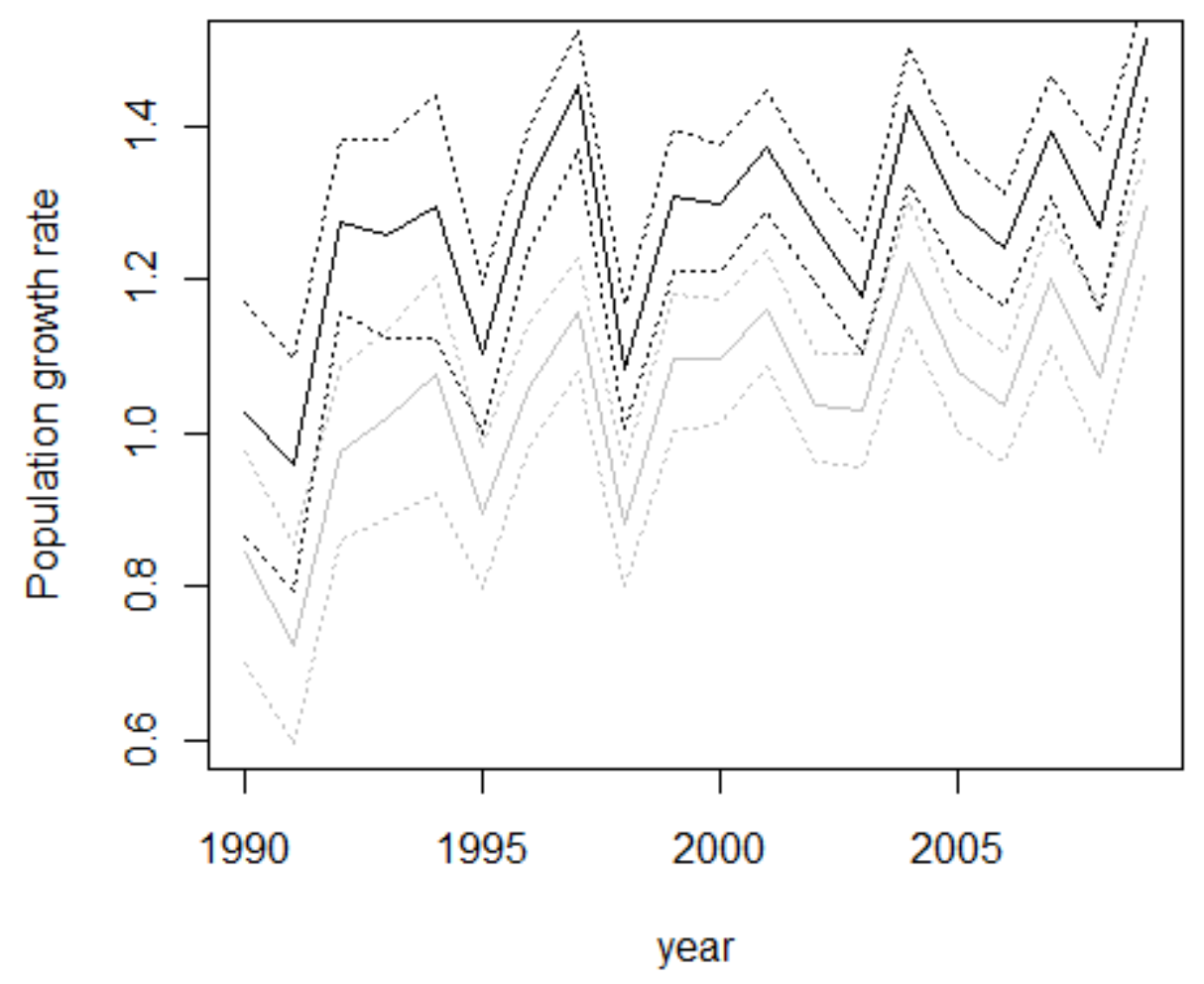

